\title{
Flora da Bahia: Asteraceae - Piptocarpha (Vernonieae: Pitpotcarphinae)
}

\author{
Maria Zugaib $^{\mathrm{a}}$ \& André Márcio Amorim*
}

Centro de Pesquisas do Cacau, Herbário CEPEC \& Departamento de Ciências Biológicas, Universidade Estadual de Santa Cruz, Ilhéus, Bahia, Brasil.

\begin{abstract}
Resumo - É apresentado o levantamento florístico de Piptocarpha (Asteraceae) no estado da Bahia, Brasil. Foram reconhecidas doze espécies: duas apresentam hábito arbóreo e dez são arbustos escandentes. Piptocarpha notata representa um novo registro para o estado, e $P$. gustavo-valerioana e $P$. riedelii são endêmicas. É apresentada uma chave de identificação, descrições morfológicas, comentários taxonômicos, mapas de distribuição geográfica e ilustrações das espécies.
\end{abstract}

Palavras-chave adicionais: Floresta Atlântica, florística, taxonomia.

\begin{abstract}
Flora of Bahia: Asteraceae - Piptocarpha (Vernonieae: Pitpotcarphinae) - A floristic survey of the Piptocarpha (Asteraceae) from Bahia State, Brazil, is presented. Twelve species were recognized, two of which are trees and ten are scandent shrubs. Piptocarpha notata represents a new record for the state, and P. gustavo-valerioana and P. riedelii are endemic. An identification key, morphological descriptions, taxonomic notes, geographic distribution maps and illustrations of the species are given.
\end{abstract}

Additional key words: Atlantic Forest, floristics, taxonomy.

\section{AsteraceAe}

Ervas, subarbustos, arbustos, raramente lianas ou árvores. Folhas alternas ou opostas, raro verticiladas, simples, lobadas ou divididas, sem estípulas. Inflorescências em capítulo, receptáculo envolvido por brácteas, solitário ou reunido em uma capitulescência, glabro ou com tricomas, areolado, aveolado com depressões ou paleáceo. Flores uni ou bissexuadas, sésseis ou subsésseis, iguais ou diferenciadas em flores do raio e disco; corola pentâmera, gamopétala, actinomorfa (tubulosa, tubuloso-filiforme) ou zigomorfa (bilabiada, ligulada, pseudobilabiada); cálice ausente ou modificado em pápus; estames 5, epipétalos, filetes livres entre si; anteras sinânteras, envolvendo o estilete e o estigma, rimosas, base truncada, sagitada, cordiforme, caudada (estéril) ou calcarada (fértil); estilete solitário, filiforme, ápice dividido em dois ramos, papilosos ou pilosos, superfícies internas estigmáticas; ovário ínfero, bicarpelar, unilocular, com um óvulo, placentação ereta. Pápus cerdosos, coroniformes, aristados ou paleáceos, presentes ou não. Fruto cipsela, cilíndrica, prismática, costelada, obovada, fusiforme, globosa ou comprimida dorso-ventralmente.

Asteraceae é a maior família de angiospermas, representando $10 \%$ da flora de eudicotiledôneas, com 24.000-30.000 espécies e 1.600-1.700 gêneros, e distribuição cosmopolita (Funk et al. 2009). No Brasil, é representada por 277 gêneros e 2061 espécies (Nakajima et al. 2014), distribuídas em todos os domínios fitogeográficos, sendo mais abundantes nas

\footnotetext{
*Autor para correspondência: amorim.uesc@gmail.com;

amariazugaib@hotmail.com

Editor responsável: Alessandro Rapini

Submetido: 25 jan. 2013; aceito: 11 out. 2014

Publicação eletrônica: 18 nov. 2014; versão final: 20 jan. 2015
}

áreas de cerrado e campo rupestre dos estados da Bahia e Minas Gerais (Roque \& Bautista 2008). Na Bahia, são listados 151 gêneros e 524 espécies (Nakajima et al. 2014).

\section{Piptocarpha R.Br.}

Arbustos escandentes, raramente árvores; ramos cilíndricos ou angulosos, estriados, tricomas estrelados ou lepidotos, raramente simples, cinéreos ou ferrugíneos, pontuações glandulares presentes ou não. Folhas alternas, coriáceas, subcoriáceas ou raramente membranáceas ou cartáceas; lâmina com margem inteira, denticulada ou raramente revoluta, discolores ou concolores, tricomas estrelados ou lepidotos, geralmente com indumento tomentoso, pontuações glandulares presentes ou não, pecíolo sulcado. Inflorescências axilares corimbimformes, glomeruliformes ou umbeliformes. Capítulos homógamos, discoides, sésseis ou pedunculados; invólucros multisseriados, ovoides, cilíndricos, campanulados ou turbinados; brácteas involucrais imbricadas em séries, ápice nigrescente, tomentoso ou raramente glabro, pontuações glandulares presentes ou não, margem ciliada ou aracnoide, brácteas externas persistentes, as internas caducas. Flores nigrescentes (quando desidratadas), corola tubulosa, pentalobada, lobos revolutos, dotados de pontuações glandulares e tricomas simples; anteras caudadas, exsertas, apêndice apical lanceolado, base das tecas truncada e com papilas ou afilada e sem papilas; estilete com ápice agudo, região externa com tricomas coletores, obtusos e na interna com papilas estigmáticas. Cipselas anguladas, 10-costadas ou indistintamente costadas, glabras ou com pontuações glandulares; pápus cerdosos, duplos, cerdas externas curtas, desiguais, filiformes ou paleáceas, cerdas internas longas, uniformes, filiforme-barbeladas. 
Piptocarpha é um gênero neotropical com aproximadamente 50 espécies (Robinson 2002; Smith \& Coile 2007). Está distribuído desde o sul do Brasil e norte da Argentina até as Antilhas e América Central (Smith 1981; Robinson 2002), tendo como principal centro de ocorrência o leste e o sul do Brasil (Smith 1981, 1982). No Brasil, apresenta ca. 30 espécies, sendo que a maioria destas ocorre em áreas de Floresta
Atlântica (Loeuille 2014). Na Bahia, foram reconhecidas 12 espécies. Piptocarpha stifftioides H.Rob., espécie conhecida por uma única coleção proveniente da Bahia, não foi incluída nesse tratamento, pois a análise do material-tipo não permitiu seu reconhecimento em Piptocarpha, como também constatado por Smith \& Coile (2007).

\section{Chave de identificação}

1. Árvores.

2. Folhas elípticas a lanceoladas, não revolutas; inflorescências glomeruliformes; invólucros cilíndricos; anteras com a base das tecas truncada e com papilas .... 5. P. macropoda subsp. crassifolia

2'. Folhas orbiculares a obovadas, irregularmente revolutas; inflorescências umbeliformes; invólucros ovoides a cilíndricos; anteras com a base das tecas afilada e sem papilas

12. $P$. rotundifolia

1 '. Arbustos escandentes.

3. Ramos angulosos.

4. Folhas subcoriáceas, elípticas, face abaxial ferrugíneo-lepidoto-tomentosa

2. P. leprosa

4'. Folhas cartáceas, lanceoladas, face abaxial cinéreo-lepidoto-tomentosa

6. P. notata

3'. Ramos cilíndricos.

5. Anteras com a base das tecas afilada e sem papilas.

6. Folhas largas, 4,5-9 cm larg., concolores, elíptico-oblongas, face adaxial rugosa; invólucros ovoides a turbinados

11. P. robusta

6'. Folhas estreitas, 1-5 cm larg., fortemente discolores, elíptico-lanceoladas, face adaxial lisa; invólucros cilíndricos 9. P. ramiflora

5'. Anteras com a base das tecas truncada e com papilas.

7. Inflorescências umbeliformes

10. $P$. riedelii

7'. Inflorescências corimbiformes ou glomeruliformes.

8. Inflorescências corimbiformes.

9. Folhas oblongas, com tricomas lepidotos na face abaxial

4. P. lundiana

9'. Folhas elípticas, com tricomas estrelados na face abaxial

1. P. gustavo-valerioana

8'. Inflorescências glomeruliformes.

10. Face abaxial das folhas com pontuações marrons

8. P. pyrifolia

10'. Face abaxial das folhas sem pontuações.

11. Folhas coriáceas, pápus amarelo-ferrugíneos com cerdas externas paleáceas e cipselas com pontuações ferrugíneas

3. P. lucida

11'. Folhas cartáceas, pápus alvos com cerdas externas filiformes e cipselas sem pontuações 7. P. oblonga subsp. Lepidota

1. Piptocarpha gustavo-valerioana G.Lom.Sm., Fl. Neotrop. Monogr. 99: 67. 2007.

Figura 1.

Arbustos escandentes; ramos cilíndricos, cinéreolepidotos, sem pontuações. Folhas elípticas, 5-7 × 2,5$3 \mathrm{~cm}$, subcoriáceas, ápice agudo a levemente acuminado, base cuneada, margem inteira, fortemente discolores, face adaxial glabra, sem pontuações, face abaxial cinéreo-estrelado-tomentosa, sem pontuações, 6-8 pares de nervuras laterais, pecíolo $0,5-1 \mathrm{~cm}$ compr. Inflorescências corimbiformes, capítulos pedunculados; invólucros $5,5-6 \times$ ca. $2,5 \mathrm{~mm}$, cilíndricos; brácteas involucrais imbricadas em 5 ou 6 séries, ferrugíneas quando desidratadas, ápice densamente tomentoso, sem pontuações, subagudo, margem aracnoide, brácteas externas ovadas, brácteas internas elípticas a elíptico-lineares. Flores com tubo (2,5-)3-4(-4,5) mm compr., lobos 2,5-3 mm compr.; anteras $3-3,5 \mathrm{~mm}$, base truncada com papilas, $0,5-1$ $\mathrm{mm}$ compr. Cipselas imaturas $1-2(-3,5) \mathrm{mm}$ compr., maduras 3-4,5 mm compr., 3-angulosas, 10-costadas, com pontuações ferrugíneas; pápus alvos, cerdas externas $0,5-1(-1,5) \mathrm{mm}$ compr., filiformes a paleáceas, cerdas internas 5-6(-7) mm compr.

Piptocarpha gustavo-valerioana é endêmica da Bahia, com distribuição na Floresta Atlântica no sul do estado (Smith \& Coile 2007; Loeuille 2014) e na Chapada Diamantina. E9, F6, F7, F8, H7, H8: Floresta Ombrófila Densa Submontana, Floresta Estacional Semidecidual. Coletada com flores e frutos em julho, agosto, novembro e dezembro.

Material selecionado - Cachoeira, RPPN da Peninha, 12³7'06"S, 3857'21"W, 5 m s.n.m., 23 jul. 2006 (fl. e fr.), J.S. Santos et al. 182 (ALCB, HUESC); Encruzilhada, saída para Itambé, 15³1'53"S, 4054'34"W, 27 maio 1968, R.P. Belém 3676 (Holótipo RB); Ibicoara, estrada Ibicoara a Cascavel, 13⒉ $248^{\prime \prime S}$, $41^{\circ} 17^{\prime} 05^{\prime \prime W}, 1027$ m s.n.m., 28 ago. 2009 (fl. e fr.), P.L.R. Moraes et al. 2945 (HUEFS); Igrapiúna, assentamento Mirante, 135'ㄹ"'S, 39²0'59"W, 48 m s.n.m., 18 dez. 2001 (fl. e fr.), L.J. Alves et al.314 (ALCB, CEPEC); Maracás, $40 \mathrm{~km}$ a leste de 


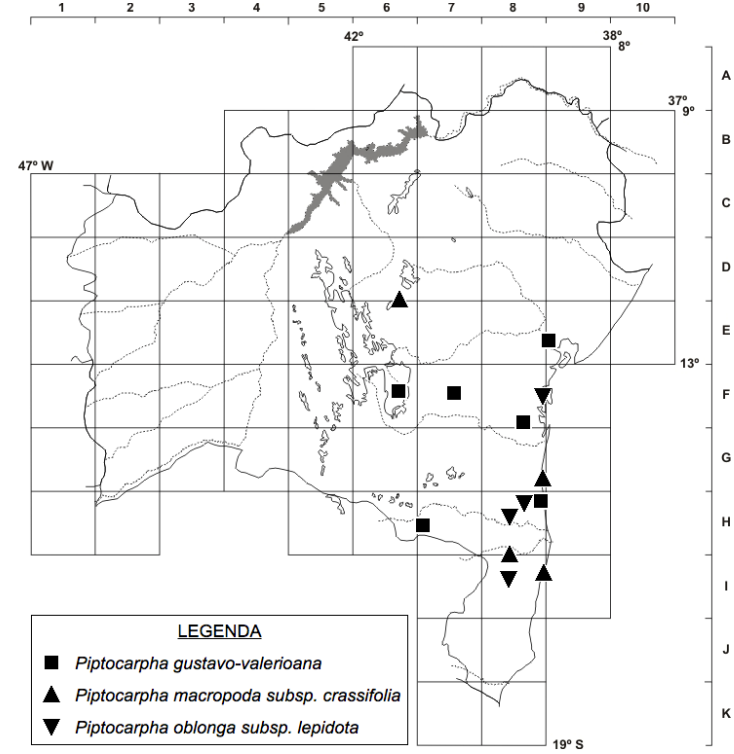

Figura 1. Distribuição geográfica de Piptocarpha gustavovalerioana, P. macropoda subsp. crassifolia e $P$. oblonga subsp. lepidota no estado da Bahia.

Maracás, 1326'28"S, 40²5'51"W, 800 m s.n.m., 13 jul. 1979 (fl. e fr.), R.M. King \& S.A. Mori 8020 (CEPEC); Una, Reserva Biológica de Una, $15^{\circ} 10^{\prime}$ S, 3904'W, 28 m s.n.m., 24 nov. 1996 (fl. e fr.), W.W. Thomas et al. 11413 (CEPEC).

Piptocarpha gustavo-valerioana é reconhecida por apresentar ramos cilíndricos cinéreo-lepidotos com pontuações glandulares hialinas, folhas elípticas fortemente discolores, com face abaxial cinéreoestrelado-tomentosa e inflorescências corimbiformes. A descrição apresentada traz um detalhamento na morfologia das cipselas maduras, até então desconhecida.

2. Piptocarpha leprosa (Less.) Baker in Martius, Fl. Bras. 6(2): 128. 1873.

Figura 2.

Arbustos escandentes; ramos 4-angulosos, cinéreoferrugíneo-lepidoto-tomentosos, pontuações ausentes. Folhas elípticas, elíptico-ovadas, (8-)10-14 × 3,5-6 $\mathrm{cm}$, subcoriáceas, ápice agudo a acuminado, base cuneada a obtusa, margem levemente ondulada e revoluta, discolores, face adaxial glabra, sem pontuações, face abaxial ferrugíneo-lepidototomentosa, raramente com pontuações, 8 ou 9 pares de nervuras laterais, pecíolo $1-1,5 \mathrm{~cm}$ compr. Inflorescências corimbiformes, capítulos pedunculados; invólucros ca. $8 \times 2-2,5 \mathrm{~mm}$, cilíndricos a estritamente turbinados; brácteas involucrais imbricadas em 5-7 séries, ferrugíneas quando desidratadas, ápice tomentoso, sem pontuações, subagudo, margem ciliada a aracnoide, brácteas externas ovado-triangulares a ovadas, brácteas internas elípticas a elíptico-lineares. Flores com tubo 3,5-4,5 mm compr., lobos ca. $3 \mathrm{~mm}$ compr.; anteras ca. 3,5 $\mathrm{mm}$ compr., base das tecas truncada, com papilas, ca. $1 \mathrm{~mm}$ compr. Cipselas imaturas $1,5-2,5(-3,5) \mathrm{mm}$ compr., maduras $3-4 \mathrm{~mm}$

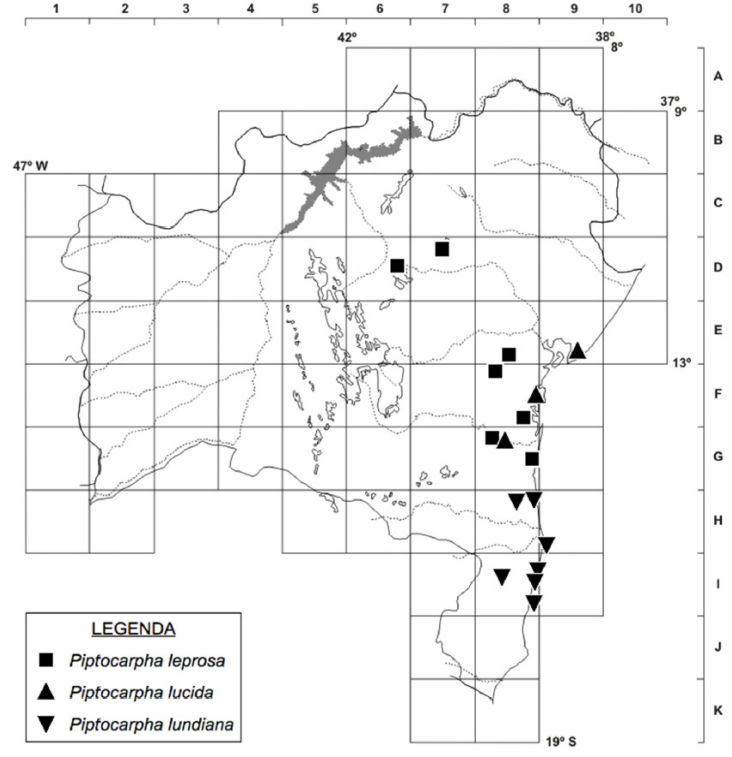

Figura 2. Distribuição geográfica de Piptocarpha leprosa, P. lucida e P. lundiana no estado da Bahia.

compr., 3-angulosas, 10-costadas, com pontuações ferrugíneas; pápus alvo-ferrugíneos, cerdas externas $0,5-1(-2) \mathrm{mm}$ compr., filiformes a paleáceas, cerdas internas 5-5,5 $\mathrm{mm}$ compr.

Piptocarpha leprosa está distribuída desde o norte da América do Sul até o sul do Brasil, ocorrendo em áreas de Floresta Atlântica da Bahia, Espírito Santo, Rio de Janeiro, Minas Gerais, São Paulo e Paraná (Smith \& Coile 2007; Loeuille 2014). D6, D7, E8, F8, G8: Floresta Ombrófila Densa Montana e Submontana, Floresta Estacional Semidecidual e Campo Rupestre. Coletada com flores e frutos em janeiro, fevereiro, abril, junho, agosto, setembro.

Material selecionado - Amargosa, Pelado, 1306'09"S, 3940'39"W, 835 m s.n.m., 18 nov. 2007 (fl e fr.), F.M. Ferreira et al. 1895 (CEPEC); Elísio Medrado, Serra da Jiboia, 1251'S, 39² $28^{\prime} \mathrm{W}, 600$ a 839 m s.n.m., 8 fev. 2011 (fl. e fr.), M.L. Guedes et al. 17931 (ALCB); Igrapiúna, Reserva da Michelin, 1351'09"S, 39¹3'78"S, 48 m s.n.m., 2 dez. 2005 (fl. e fr.), R. Sambuichi et al. 555 (HUESC, SPF); Itagibá, Mata da Portaria, $14^{\circ} 10^{\prime} 02^{\prime \prime S}, 39^{\circ} 43^{\prime} 20^{\prime \prime} \mathrm{W}, 185$ m s.n.m., 10 ago. 2008 (fl. e fr.), C.E. Ramos et al. 254 (ALCB); Jacobina, Serra do Tombador,

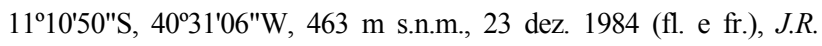
Pirani et al. 7464 (SPF); Morro do Chapéu, fazenda Guariba, $11^{\circ} 26^{\prime} 21^{\prime \prime S}, 41^{\circ} 11^{\prime} 35^{\prime \prime W}, 1067$ m s.n.m., 28 abr. 2011 (fl. e fr.), E. Melo et al. 9612 (HUEFS); Uruçuca, Parque Estadual da Serra do Conduru, 14³0'19"S, 3906'26"W, 102 m s.n.m., 29 set. 1999 (fl. e fr.), A.M. Amorim et al. 3136 (CEPEC, HRB).

Piptocarpha leprosa apresenta tricomas lepidotos na face adaxial da folha $\mathrm{e}$ inflorescências corimbiformes, assim como P. notata. No entanto, em $P$. leprosa, os ramos são fortemente angulosos e as folhas subcoriáceas, elípticas, com face abaxial ferrugíneo-lepidoto-tomentosa, enquanto $P$. notata possui ramos levemente angulosos e folhas cartáceas, lanceoladas, com a face abaxial cinéreo-lepidototomentosa. 
3. Piptocarpha lucida (Spreng.) Benn. ex Baker in Martius, Fl. Bras. 6(2): 121. 1873.

Figuras 2 e 3 A.

Arbustos escandentes; ramos cilíndricos, cinéreoestrelados, sem pontuações. Folhas elípticas, elípticoovadas, 5-8,5(-10) $\times 3-5 \mathrm{~cm}$, coriáceas, ápice acuminado, base cuneada ou obtusa a arredondada, raramente oblíqua, margem inteira, levemente revoluta, discolores, face adaxial glabra, sem pontuações, face abaxial ferrugíneo-estrelado-tomentosa, sem pontuações, 6-8 pares de nervuras laterais, pecíolo (6) 8-11 mm compr. Inflorescências glomeruliformes, capítulos sésseis; brácteas involucrais amareloferrugíneas quando desidratadas, ápice tomentoso, sem pontuações, subagudo, margem ciliada a aracnoide, brácteas externas ovadas, brácteas internas elípticas a elíptico-lineares. Flores com tubo $4-4,5 \mathrm{~mm}$ compr., lobos 2,5-3 mm compr.; anteras 3-3,5 mm compr., base das tecas truncada, com papilas, ca. $1 \mathrm{~mm}$ compr. Cipselas maduras 3-3,5 mm compr., 3-angulosas, 10costadas, com pontuações ferrugíneas; pápus amareloferrugíneos, cerdas externas 0,5(-1) $\mathrm{mm}$ compr., paleáceas, cerdas internas (5-)5,5-6 mm compr.

Piptocarpha lucida é endêmica do Brasil e está distribuída em áreas de Floresta Atlântica da Bahia, Rio de Janeiro e São Paulo (Barroso 1959; Smith \& Coile 2007; Loeuille 2014). E9, F8, G8: Floresta Ombrófila Densa Submontana. Coletada com flores e frutos em março, novembro e dezembro.

Material selecionado - Cairu, 13⒉ $29^{\prime} 13^{\prime \prime S}, 39^{\circ} 02^{\prime} 38^{\prime \prime} \mathrm{W}, 19 \mathrm{~m}$ s.n.m., 9 dez. 1980 (fl. e fr.), A.M. Carvalho et al. 397 (CEPEC, RB); Simões Filho, 12²47'02"S, 38²4'W, 52 m s.n.m., 14 nov. 1980 (fl. e fr.), E. Gusmão \& P. Souza 497 (ALCB, CEPEC, HUEFS, RB); Ubatã, fazenda Rancho Alegre, 14¹2'50"S, 39³1'22"W, 109 m s.n.m., 25 mar. 1993 (fl. e fr.), A.M. Carvalho et al. 4227 (CEPEC, HRB, RB).

Piptocarpha lucida se assemelha morfologicamente a P. oblonga subsp. lepidota pela presença de ramos cilíndricos, delgados e fortemente flexuosos, além de apresentarem folhas amarronzadas quando secas, com a face abaxial recoberta por tricomas estrelados. No entanto, $P$. lucida difere por apresentar folhas coriáceas e elípticas, pápus amarelo-ferrugíneos com cerdas externas paleáceas e cipselas com pontuações glandulares ferrugíneas (vs. folhas cartáceas e ovadolanceoladas, pápus alvos com cerdas externas filiformes e cipselas sem pontuações glandulares em $P$. oblonga subsp. lepidota). $\mathrm{O}$ material herborizado não permite observar o formato do invólucro porque as brácteas internas são decíduas.

4. Piptocarpha lundina (Less.) Baker in Martius, Fl. Bras. 6(2): 130; t. 29. 1873.

Figuras 2 e 3 B-D.

Arbustos escandentes; ramos cilíndricos, cinéreoferrugíneo-lepidoto-tomentosos, sem pontuações. Folhas oblongas, (7-)9-16 × 3,5-5(-7) cm, coriáceas, raramente cartáceas, ápice obtuso a arredondado, base cuneada a obtusa, margem inteira, levemente revoluta, discolores, face adaxial glabrescente, sem pontuações, face abaxial ferrugíneo-cinéreo-lepidoto-tomentosa, sem pontuações, até 8 pares de nervuras laterais, pecíolo 2-3 cm compr. Inflorescências corimbiformes, capítulos sésseis; invólucros ca. $5 \times 3 \mathrm{~mm}$, campanulados; brácteas involucrais imbricadas em 4 ou 5 séries, castanho-ferrugíneas quando desidratadas, ápice tomentoso, sem pontuações, agudo, margem ciliada, brácteas externas ovado-triangulares, brácteas internas elípticas a elíptico-oblongas. Flores com tubo ca. $5 \mathrm{~mm}$ compr., lobos ca. $2 \mathrm{~mm}$ compr.; anteras ca. 3 $\mathrm{mm}$ compr., base das tecas truncada, com papilas, ca. $0,5 \mathrm{~mm}$ compr. Cipselas imaturas ca. $1,5 \mathrm{~mm}$ compr., maduras 2,5-3(-4) $\mathrm{mm}$ compr., 3-angulosas, 10costadas, com pontuações hialinas; pápus alvoferrugíneos, cerdas externas $(0,8-) 1-1,5 \mathrm{~mm}$ compr., paleáceas, cerdas internas $5,5-6 \mathrm{~mm}$ compr

Piptocarpha lundiana é endêmica do Brasil e está distribuída em áreas de Floresta Atlântica no sul da Bahia, Espírito Santo, Rio de Janeiro e Minas Gerais (Smith \& Coile 2007; Loeuille 2014). H8, H9, I8: Floresta Ombrófila Densa Montana e Submontana. Coletada com flores e frutos em abril e de julho a novembro.

Material selecionado - Arataca, Serra do Peito de Moça, $15^{\circ} 15^{\prime} 25^{\prime \prime S}, 39^{\circ} 20^{\prime} 30^{\prime \prime W}, 1000$ m s.n.m., 12 out. 2005 (fl. e fr.), A.M. Amorim et al. 5245 (ALCB, CEPEC); Belmonte, 15 51'47"S, 38 52'58"W, 8 m s.n.m., 26 jul. 1988 (bt.), T.S. Santos et al. 4401 (ALCB, CEPEC); Eunápolis, 16²2'19"S, 39³4'49"W, $189 \mathrm{~m}$ s.n.m., 28 set. 1966 (bt.), R.P. Belém \& R. Pinheiro 2654 (CEPEC, $\mathrm{RB})$; Ilhéus, fazenda Ipiranga, $16^{\circ} 46^{\prime} 55^{\prime \prime} \mathrm{S}, 39^{\circ} 04^{\prime} 09^{\prime \prime} \mathrm{W}, 52 \mathrm{~m}$ s.n.m., 25 out. 1972 (fl. e fr.) R.S. Pinheiro 1937 (CEPEC); Porto Seguro, Parque Nacional de Monte Pascoal, 16²6'59"S, 39 03'53"W, 49 m s.n.m., 14 nov. 1996 (fl. e fr.), W.W. Thomas et al. 11324 (CEPEC); Santa Cruz Cabrália, Mata Cara-Branca, $16^{\circ} 16^{\prime} \mathrm{S}, 39^{\circ} 01^{\prime} \mathrm{W}, 32 \mathrm{~m}$ s.n.m., 22 out. 1999 (fl. e fr.), M.L. Guedes et al. 6759 (ALCB); Una, Reserva Biológica de Una, 1509'S, $39^{\circ} 05^{\prime}$ W, 28 m s.n.m., 14 set. 1993 (fl. e fr.), A.M. Amorim et al. 1377 (CEPEC, HUEFS).

Dentre as espécies de Piptocarpha na Bahia, $P$. lundiana é facilmente reconhecida por apresentar folhas oblongas, fortemente discolores, com tricomas lepidotos ferrugíneos e cinéreos na face abaxial, e inflorescências densamente corimbiformes. A maioria das exsicatas examinadas apresentava capítulos jovens com flores em botão e cipselas ainda em formação.

5. Piptocarpha macropoda (DC.) Baker subsp. crassifolia (Baker) G.Lom.Sm., Fl. Neotropica Monogr. 99: 77 (2007). Figura 1.

Árvores (3,5-)5-10 m alt; ramos cilíndricos, ferrugíneo-cinéreo-estrelado-tomentosos, sem pontuações. Folhas elípticas, (6-)12-15 × 3-5 cm, subcoriáceas, ápice agudo, base aguda a cuneada, margem inteira, levemente revoluta, discolores, face adaxial glabrescente, pontuações ausentes, face abaxial ferrugíneo-estrelado-tomentosa, sem pontuações, 10 ou 11 pares de nervuras laterais, pecíolo 1,5-2 cm compr. Inflorescências glomeruliformes, capítulos sésseis; invólucros 7,5-8 × 2-3,5 mm, 
estreitamente turbinados; brácteas involucrais imbricadas em 4-6 séries, castanho-ferrugíneas quando desidratadas, ápice tomentoso, sem pontuações, agudo, margem escassamente aracnoide, brácteas externas ovadas, brácteas internas elípticas a elíptico-lineares. Flores com tubo 3,5-4 mm compr., lobos 1,5-2 mm compr.; anteras 2,5-3 $\mathrm{mm}$ compr., base das tecas truncada, com papilas, 0,5-1 $\mathrm{mm}$ compr. Cipselas imaturas 2-2,5 mm compr., maduras 3-4 mm compr., 3- ou 4-angulosas, indistintamente costadas, com pontuações ferrugíneas; pápus amarelos, cerdas externas ca. $1 \mathrm{~mm}$ compr., paleáceas, cerdas internas 5-6 mm compr.

Piptocarpha macropoda subsp. crassifolia é endêmica do Brasil, ocorrendo nos estados da Bahia, Minas Gerais, Rio de Janeiro, São Paulo, Distrito Federal e em todos os estados da Região Sul (Smith \& Coile 2007; Loeuille 2014). D6, G8, H8, I8: encontrada em Floresta Ombrófila Densa Submontana e Floresta Estacional Semidecidual. Coletada com flores e frutos em outubro e novembro.

Material selecionado - Ilhéus, Vila Brasil, 16046'55"S, 3904'09"W, 100 m s.n.m., 27 out. 1979 (fl. e fr.), S.A. Mori \& F Benton 12883 (CEPEC, RB); Itapebi, fazenda João das Orquídeas, $15^{\circ} 56^{\prime} 15^{\prime \prime S}, 39^{\circ} 33^{\prime} 45^{\prime \prime} \mathrm{W}, 177$ m s.n.m., 13 out. 2007 (fl. e fr.), F.M. Ferreira et al. 1532 (CEPEC); Bonito, estrada Bonito/Utinga,

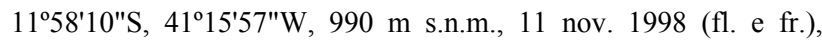
F.H.F. Nascimento 75 (HUEFS); Santa Cruz Cabrália, Torre da Embratel, $16^{\circ} 16^{\prime} \mathrm{S}, 39^{\circ} 01^{\prime} \mathrm{W}, 220 \mathrm{~m}$ s.n.m., 17 out. 1978 (fl. e fr.), $S$ A. Mori et al. 10769 (CEPEC, RB).

Piptocarpha macropoda subsp. crassifolia é o único táxon na Floresta Atlântica da Bahia que apresenta hábito arbóreo. As folhas são elípticas a lanceoladas e discolores, com tricomas ferrugíneoestrelados na face abaxial e inflorescência densamente glomeruliforme. Segundo Smith \& Coile (2007), P. macropoda subsp. crassifolia difere de $P$. macropoda subsp. macropoda por possuir folhas elípticas a ovadolanceoladas e invólucros com 9-11 × 5-6 mm (vs. folhas largamente ovadas e invólucros maiores, 11-13 $\times$ 6,5-7,5 mm em P. macropoda subsp. macropoda). Estas informações serviram como suporte para o reconhecimento e adoção da subespécie.

6. Piptocarpha notata (Less.) Baker in Martius, Fl. Bras. 6(2): 129. 1873.

Figuras 3E-H e 4.

Arbustos escandentes; ramos levemente angulosos, cinéreo-lepidoto-tomentosos, pontuações ausentes. Folhas elíptico-lanceoladas, 11-15(-19) × 3-4(-5) cm, cartáceas, ápice agudo, base cuneada, margem espaçadamente denticulada, fortemente discolores, face adaxial glabra, sem pontuações, face abaxial cinéreolepidoto-tomentosa, com pontuações hialinas, 6-9 pares de nervuras laterais, pecíolo 1,5-2 cm compr. Inflorescências corimbiformes, capítulos sésseis; brácteas involucrais ferrugíneas (quando desidratadas), ápice tomentoso, sem pontuações, agudo, margem aracnoide, brácteas externas ovadas, brácteas internas elípticas a elíptico-lineares. Flores com tubo 3,5-4 mm compr., lobos 3-3,5 mm compr.; anteras 2,5-3 mm compr., base das tecas truncada, com papilas, ca. 0,5 mm compr. Cipselas (maduras) 4-4,5 mm compr., 3angulosas, 10-costadas, com pontuações ferrugíneas; pápus alvos, cerdas externas ca. $0,5 \mathrm{~mm}$ compr., filiformes a paleáceas, cerdas internas ca. $5,5 \mathrm{~mm}$ compr.

Piptocarpha notata é endêmica do Brasil e está distribuída em áreas de Floresta Atlântica do Espírito Santo, Rio de Janeiro, Minas Gerais e São Paulo (Smith \& Coile 2007; Loeuille 2014). H8: Floresta Ombrófila Densa Montana. Coletada com flores e frutos em janeiro, março, maio, outubro e dezembro.

Material selecionado - Camacan, RPPN Serra Bonita, 15²3'30"S, 39³3'55"W, 300 a 1080 m s.n.m., 19 mar. 2007 (fl. e fr.), R.A.X. Borges et al. 279 (CEPEC, HUEFS, RB); São José da Vitória, estrada São José/Una, $15^{\circ} 05^{\prime} 47^{\prime \prime S}, 39^{\circ} 19^{\prime} 11^{\prime \prime W}, 500$ a 700 m s.n.m., 8 jan. 2001 (fl. e fr.), A.M. Amorim et al. 3611 (CEPEC).

Material adicional examinado - BRASIL. MINAS GERAIS: Paraopeba, 19¹6'26"S, 44²4'14"W, 706-1065 m s.n.m., 8 out. 1958 (fl. e fr.), E.P. Heringer 9465 (RB). ESPÍRITO SANTO: Nova Venécia, estrada do Cristalino, $18^{\circ} 42^{\prime} 38^{\prime \prime} \mathrm{S}, 40^{\circ} 24^{\prime} 02^{\prime \prime} \mathrm{W}, 65 \mathrm{~m}$ s.n.m., 17 out. 1953 (fl. e fr.), A.P. Duarte \& J.C. Gomes 3719/473 (RB).

Piptocarpha notata é reconhecida por apresentar ramos levemente angulosos, folhas cartáceas, lanceoladas, fortemente discolores, com face abaxial cinérea, margem espaçadamente denticulada e inflorescências corimbiformes. Segundo Smith \& Coile (2007), P. notata possui tricomas estrelados na face abaxial da folha, porém observamos que eles são lepidotos. $\mathrm{O}$ material examinado não permitiu descrever o formato do invólucro porque as brácteas internas são decíduas. Este é o primeiro registro de $P$. notata no estado da Bahia.

7. Piptocarpha oblonga (Gardn.) Baker subsp. lepidota (Sch. Bip.) G.Lom.Smith, Martius Fl. Bras. 6(2): 121.1873.

Figuras 1 e 3I-K.

Arbustos escandentes; ramos cilíndricos, cinéreolepidoto-tomentosos, pontuações ausentes. Folhas elípticas, ovado-lanceoladas, 6-8,5 $\times 1,5-2,5 \mathrm{~cm}$, cartáceas, raramente subcoriáceas, ápice agudo, base obtusa a arredondada, margem inteira, levemente revoluta, fortemente discolores, face adaxial glabra, pontuações ausentes, face abaxial ferrugíneo-estreladotomentosa ou cinéreo-lepidoto-tomentosa, sem pontuações, 7-10 pares de nervuras laterais, pecíolo 1$1,5 \mathrm{~cm}$ compr. Inflorescências glomeruliformes, capítulos sésseis; invólucros ca. $9 \times 2 \mathrm{~mm}$, cilíndricos; brácteas involucrais imbricadas em 3 ou 4 séries, castanho-ferrugíneas quando desidratadas, ápice levemente tomentoso, sem pontuações, agudo, margem ciliada, brácteas externas ovadas, brácteas internas elípticas a elíptico-lineares. Flores (em botão) com tubo ca. 3,5 mm compr., lobos ca. 2,5 mm compr.; anteras ca. 2,5 $\mathrm{mm}$ compr., base das tecas truncada, com papilas, ca. 0,5 mm compr. Cipselas (imaturas) (1,5-)2-2,5(-3) 


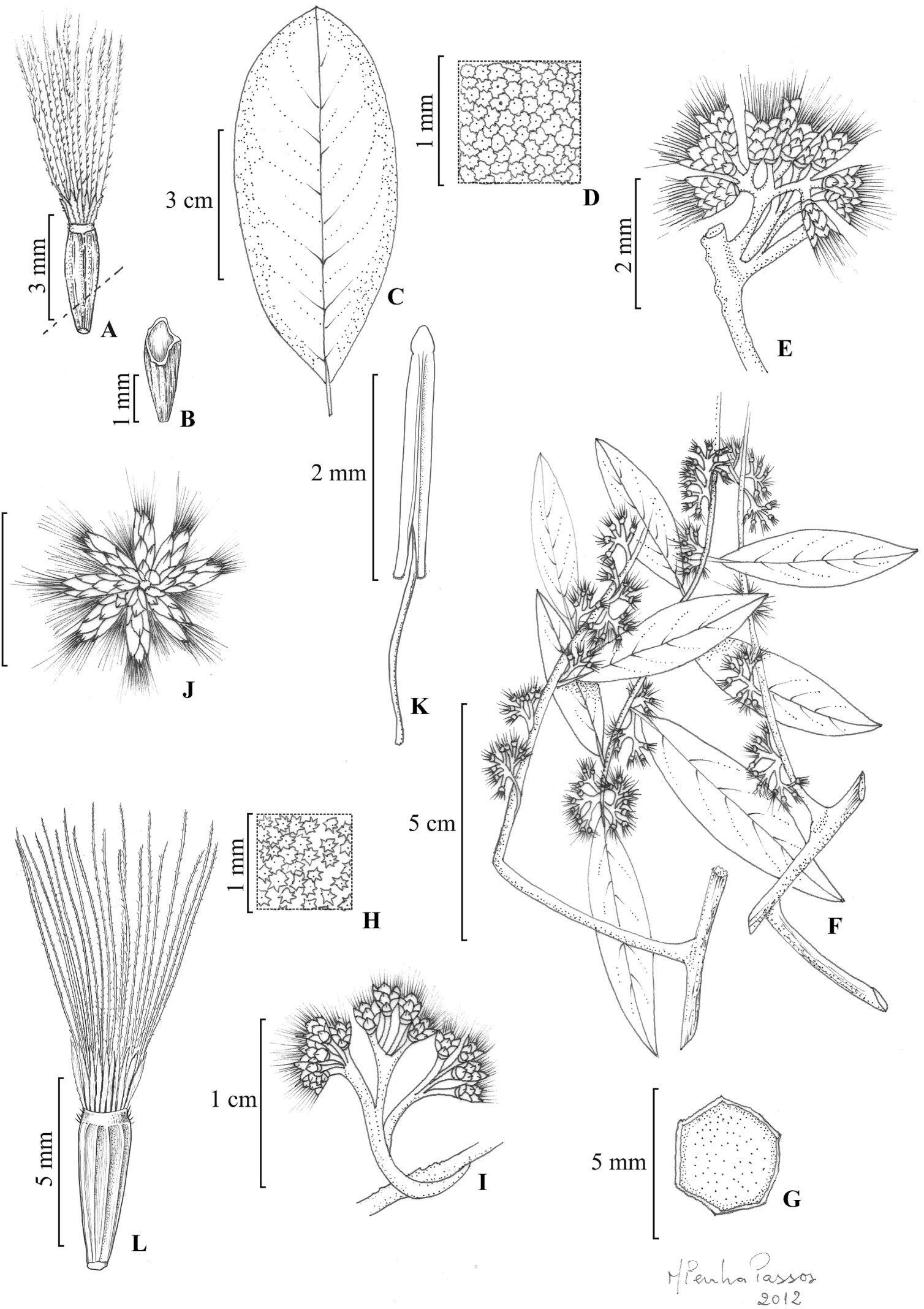

Figura 3. A-B. Piptocarpha lucida: A- cipsela com pontuações glandulares, pápus externos paleáceos e internos filiformes; B- detalhe da cipsela em corte transversal; C-E. P. lundiana: C- lâmina foliar; D- detalhe da face abaxial da lâmina foliar evidenciando os tricomas lepidotos; E- inflorescência corimbiforme; F-I. P. notata: F- ramo com inflorescências axilares corimbiformes; G- detalhe do ramo em corte transversal; H- detalhe da face abaxial da lâmina foliar evidenciando os tricomas lepidotos; I- inflorescência corimbiforme; J-L. P. oblonga: J- inflorescência glomeruliforme; K- estame, vista lateral; L- cipsela sem pontuações glandulares, pápus externos e internos filiformes. (AB- Carvalho 397; C-E- Pinheiro 1937; F-I- Amorim 3611; J-L- Amorim 7688). 
mm compr., 3-angulosas, indistintamente costadas, sem pontuações; pápus alvos, cerdas externas 1-1,5 mm compr., filiformes, cerdas internas 5-5,5 mm compr.

Piptocarpha oblonga subsp. lepidota é endêmica do Brasil, ocorrendo na Bahia, Espírito Santo, Rio de Janeiro, São Paulo, Paraná e Santa Catarina (Smith \& Coile 2007; Loeuille 2014). F8, H8, I8: Floresta Ombrófila Densa Montana e Submontana. Coletada com flores e frutos de agosto a outubro.

Material selecionado - Arataca, Serra Novo Javi, $15^{\circ} 10^{\prime} 42^{\prime \prime} \mathrm{S}$, 39²0'09"W, 759 m s.n.m., 12 set. 2009, L. Daneu 108 (CEPEC);

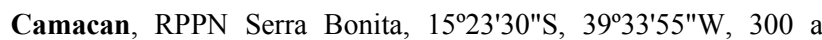
1080 m s.n.m., 31 ago. 2008 (fl. e fr.), A.M. Amorim et al. 7688 (CEPEC); Cairu, 13⒉ $9^{\prime} 13^{\prime \prime S}, 39^{\circ} 02^{\prime} 38^{\prime \prime} \mathrm{W}, 19$ m s.n.m., 25 out. 1984 (fl. e fr.), L.A. Mattos Silva et al. 1786 (CEPEC, HUEFS, RB); Eunápolis, 16²2'19"S, 39³4'49"W, 189 m s.n.m., 28 set. 1966 (fl. e fr.), R.P. Belém \& R.S. Pinheiro 2651 (CEPEC, RB).

Piptocarpha oblonga subsp. lepidota apresenta ramos com indumento cinéreo-lepidoto, inflorescências glomeruliformes, capítulos cilíndricos e pápus com cerdas externas filiformes. Observou-se que amostras desta espécie possuem uma variação no formato das folhas e nos tipos de tricomas em sua face abaxial. Segundo Smith \& Coile (2007), P. oblonga subsp. lepidota apresenta flores e cipselas maiores quando comparadas com as de $P$. oblonga subsp. oblonga. Estas informações serviram como suporte para a identificação da subespécie.

8. Piptocarpha pyrifolia (DC.) Baker in Martius, Fl. Bras. 6(2): 120; t. 27. 1836.

Figuras 5 e $6 \mathrm{~A}-\mathrm{C}$.

Arbustos escandentes; ramos cilíndricos, cinéreolepidoto-tomentosos, com pontuações marrons. Folhas $5-8(-14) \times(1,5-) 3,5-5(-7,5) \mathrm{cm}$, coriáceas, elípticas, ápice obtuso a acuminado, raramente emarginado, base cuneada, margem inteira, levemente revoluta, concolores, face adaxial glabra, com pontuações marrons, face abaxial cinéreo-lepidota, com pontuações marrons, 7-9 pares de nervuras laterais, pecíolo 1-1,5 cm compr. Inflorescências glomeruliformes, capítulos pedunculados; invólucros 5-7 × 3-4 mm, cilíndricos; brácteas involucrais imbricadas em 5 ou 6 séries, castanho-ferrugíneas quando desidratadas, ápice glabro, com pontuações marrons, obtuso, margem ciliada a aracnoide, brácteas externas ovadas a elípticas, brácteas internas elípticas. Flores com tubo 3,5-4,5 mm compr., lobos 3,5-4,5 mm compr.; anteras 2,5-3(-3,5) mm compr., base das tecas truncada, com papilas, $0,5(-1) \mathrm{mm}$ compr. Cipselas imaturas 2,5-3 mm compr., maduras 3,5-4,5 mm compr., 3-angulosas, 10-costadas, sem pontuações; pápus alvos, cerdas externas $0,5-2 \mathrm{~mm}$ compr., filiformes, cerdas internas 5-6 mm compr.

Piptocarpha pyrifolia é endêmica do Brasil e está distribuída em áreas de Floresta Atlântica da Bahia e em todos os estados da Região Sudeste (Smith \& Coile 2007; Loeuille 2014). F8, G8, H8, I8: Floresta
Ombrófila Densa Montana e Submontana. Coletada com flores e frutos em janeiro e de agosto a novembro.

Material selecionado - Almadina, Serra do Corcovado, 14ㄴㄹ'21"S, 39³6'12"W, 650 a 900 m s.n.m., 12 ago. 2007 (fl. e fr.), D. Cardoso et al. 2124 (CEPEC); Arataca, Serra Novo Javi, 15¹0'42"S, 39 $20^{\prime} 09^{\prime \prime}$ W, 759 m s.n.m., 12 set. 2009 (fl. e fr.), L. Daneu et al. 116 (CEPEC); Ilhéus, Olivença, 14\%47'20"S, 3902'58"W, 52 m s.n.m., 12 out. 1972 (fr.), T.S. Santos 2450 (CEPEC). Ituberá, BR - 001/praia de Pratigi - Rio Pancada Rasa, $13^{\circ} 43^{\prime} 56^{\prime \prime S}, 39^{\circ} 08^{\prime} 57^{\prime \prime W}, 27$ m s.n.m., 15 out. 1998 (fl. e fr.), G. Hatschbach \& J.M. Silva 68523 (ALCB); Maraú, 1406'11"S, 3900'53"W, 36 m s.n.m., 5 out. 1965 (fl. e fr.), R.P. Belém 1831 (CEPEC, RB); Nilo Peçanha, próximo ao povoado de São Francisco, 1335'58"S, 3906'25"W, 80 m s.n.m., 22 set. 1988 (fl. e fr.), L.A. Mattos Silva et al. 2579 (ALCB, CEPEC, RB); Porto Seguro, $16^{\circ} 26^{\prime} 59^{\prime \prime} \mathrm{S}, 39^{\circ} 03^{\prime} 53^{\prime \prime} \mathrm{W}, 49$ m s.n.m., s.d. (fl. e fr.), A.P. Duarte 6147 (CEPEC, RB); Santa Cruz Cabrália, $16^{\circ} 16^{\prime} \mathrm{S}, 39^{\circ} 01^{\prime} \mathrm{W}, 32$ m s.n.m., 22 out. 1999 (fr.), M.L. Guedes et al. 6758 (ALCB, CEPEC); Una, Reserva Biológica de Una, 1509'S, 3905'W, 28 m s.n.m., 13 set. 1993 (fl. e fr.), A.M. Amorim et al. 1347 (ALCB, CEPEC, HRB); Uruçuca, Parque Estadual Serra do Conduru, 14² $28^{\prime}, 39^{\circ} 05^{\prime} 06^{\prime \prime} \mathrm{W}, 50$ a $100 \mathrm{~m}$ s.n.m., 28 jan. 1999 (fr.), W.W. Thomas et al. 11870 (CEPEC). Wenceslau Guimarães, Reserva Estadual de Wenceslau Guimarães, 13ํ1'13"S, 39²8'46"W, 178 m s.n.m., 29 ago. 1991 (fl. e fr.), S.C. Sant'Ana et al. 27 (ALCB, CEPEC).

Material adicional examinado - BRASIL. RIO DE JANEIRO: Rio de Janeiro, Pedra da Gávea, 19 out. 1946, A.P. Duarte 381 (holótipo de Piptocarpha carioca G.M.Barroso, RB).

Piptocarpha pyrifolia apresenta folhas fortemente concolores, com nervuras secundárias finamente reticuladas e salientes, e pontuações glandulares marrons em ambas as faces da lâmina foliar e no ápice das brácteas involucrais, características que diferem da maioria das espécies de Piptocarpha da Bahia. Piptocarpha carioca é considerada sinônimo desta espécie (Smith \& Coile 2007).

9. Piptocarpha ramiflora (Spreng.) Baker in Martius, Fl. Bras. 6(2): 130. 1873.

Figuras 5 e 6D-G.

Arbustos escandentes; ramos cilíndricos, cinéreolepidoto-tomentosos, sem pontuações. Folhas elípticolanceoladas, (3-)4,5-13,5 × 1-5 cm, cartáceas, ápice agudo a acuminado, base cuneada a obtusa, margem denticulada, fortemente discolores, face adaxial glabrescente, sem pontuações, face abaxial cinéreoestrelado-tomentosa, sem pontuações, 7-10 pares de nervuras laterais, pecíolo $0,5-1 \mathrm{~cm}$ compr. Inflorescências umbeliformes, capítulos pedunculados; invólucros 8-9 × 3-4 $\mathrm{mm}$, cilíndricos; brácteas involucrais imbricadas em 6-8(9) séries, castanhas quando desidratadas, ápice levemente tomentoso, sem pontuações, subagudo a obtuso, margem escassamente ciliada, brácteas externas ovado-triangulares, brácteas internas elípticas a elíptico-lineares. Flores com tubo 4-5 mm compr., lobos ca. 2 mm compr.; anteras 4-4,5 $\mathrm{mm}$ compr., base das tecas afilada, sem papilas, ca. 1 mm compr. Cipselas maduras ca. $3 \mathrm{~mm}$ compr., 3angulosas, 10-costadas, com pontuações ferrugíneas; pápus alvos, cerdas externas ca. $1 \mathrm{~mm}$ compr., filiformes, cerdas internas 5-5,5 mm compr. 
Piptocarpha ramiflora é endêmica do Brasil e está distribuída em áreas de Floresta Atlântica da Bahia, Espírito Santo, Rio de Janeiro e Minas Gerais (Smith \& Coile 2007; Loeuille 2014). G8, H8: Floresta Ombrófila Densa Montana e Submontana e Floresta Estacional Semidecidual. Coletada com flores e frutos em agosto e outubro.

Material selecionado - Itabuna, fazenda Marineda, 1447'08"S, 39²16'49"W, 54 m s.n.m., 13 out. 1967 (fl. e fr.), R.S. Pinheiro 267 (CEPEC, RB); Jussari, RPPN Serra do Teimoso, 1509'29"S, 39³1'43"W, 200 a 850 m s.n.m., 13 ago. 1998 (fl. e fr.), A.M. Amorim et al. 2449 (CEPEC, HUESC).

Piptocarpha ramiflora é reconhecida por apresentar ramos cilíndricos, delgados, folhas fortemente discolores, com margem denticulada e revestida por tricomas cinéreo-estrelados na face abaxial. Apresenta inflorescências umbeliformes compostas de capítulos cilíndricos e as brácteas involucrais internas, diferentemente da maioria das outras espécies de Piptocarpha da Bahia, são imbricadas de forma compacta, o que facilita a visualização do formato dos capítulos. Na lista de espécie da flora do Brasil, Loeuille (2014) aponta pela primeira vez a ocorrência desta espécie para Bahia.

10.Piptocarpha riedelii (Sch. Bip.) Baker in Martius, Fl. Bras. 6(2): 124. 1873.

Figuras 4 e $6 \mathrm{H}-\mathrm{J}$.

Arbustos escandentes; ramos cilíndricos, cinéreolepidoto-tomentosos, com pontuações hialinas. Folhas elípticas, elíptico-oblongas, 8-13(-18) × 3-5 cm, membranáceas, ápice acuminado, base cuneada, margem inteira, levemente revoluta, concolores, face adaxial glabrescente, sem pontuações, face abaxial ferrugíneo-

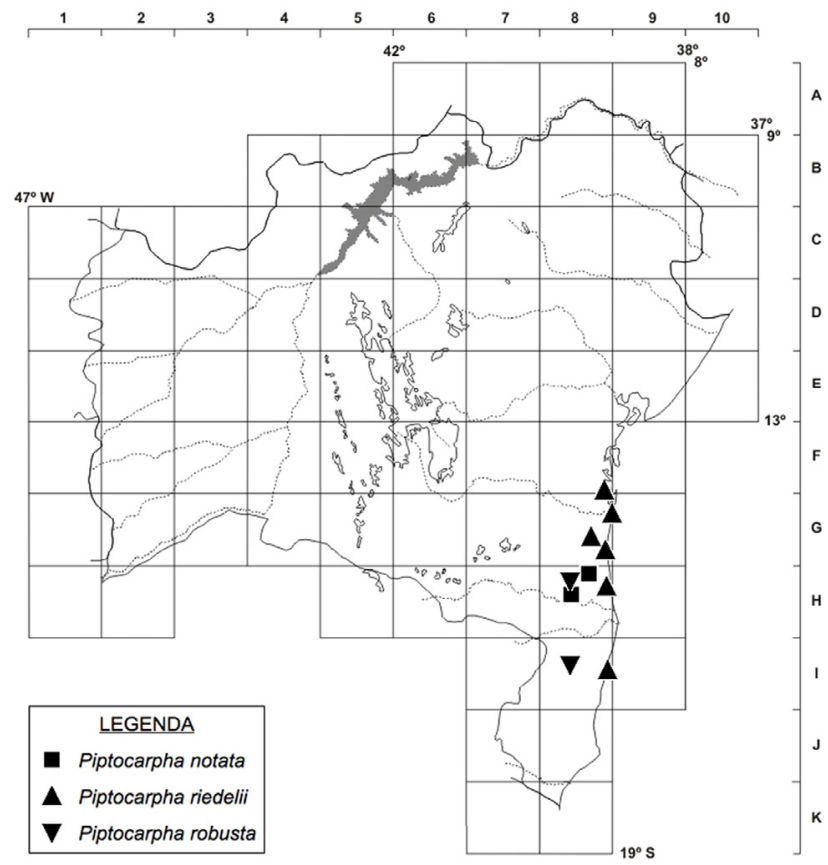

Figura 4. Distribuição geográfica de Piptocarpha notata, P. riedelii e $P$. robusta no estado da Bahia.

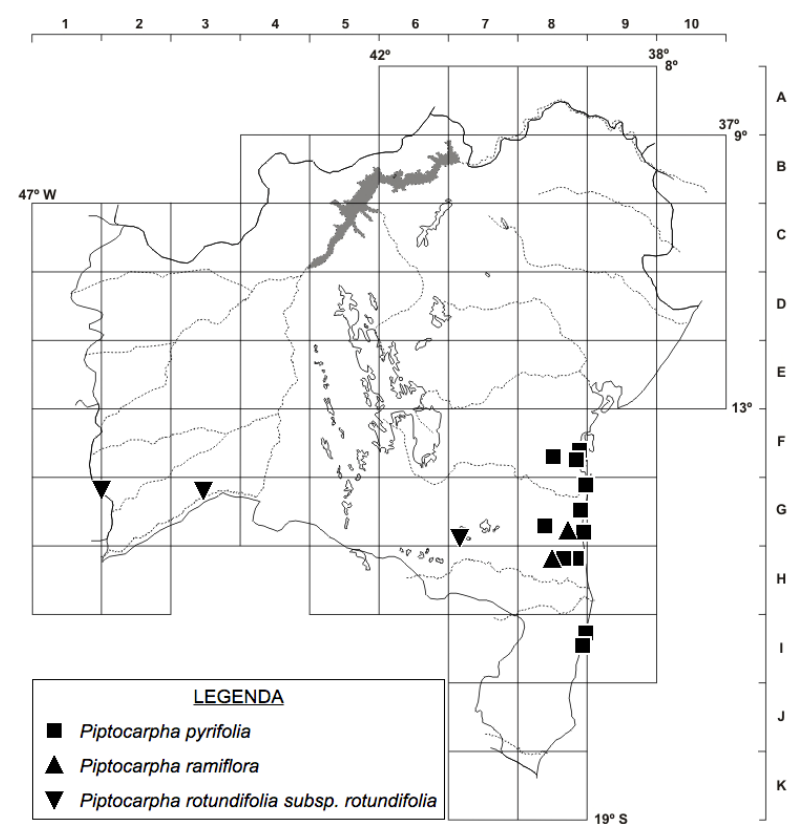

Figura 5. Distribuição geográfica de Piptocarpha pyrifolia, $P$. ramiflora e $P$. rotundifolia subsp. rotundifolia no estado da Bahia.

lepidoto-tomentosa, sem pontuações, 7-10 pares de nervuras laterais, pecíolo 0,7-1,5 cm compr. Inflorescências umbeliformes, capítulos curtamente pedunculados; invólucros $6-8 \times 2-2,5 \mathrm{~mm}$, cilíndricos a campanulados; brácteas involucrais imbricadas em 57 séries, marrons quando desidratadas, ápice levemente tomentoso, sem pontuações, obtuso, margem ciliada, brácteas externas ovadas, brácteas internas elípticas a elíptico-oblongas. Flores com tubo 5-6,5 $\mathrm{mm}$ compr., lobos 3-3,5(-4) mm compr.; anteras 4-4,5 mm compr., base das tecas truncada, com papilas, 0,5-1 $\mathrm{mm}$ compr. Cipselas imaturas 3-4 mm compr., maduras 4,5-5 mm compr., 3-angulosas, 10-costadas, com pontuações hialinas; pápus marrom-dourados, cerdas externas $0,5-1$ mm compr., paleáceas, cerdas internas 6-7 mm compr.

Piptocarpha riedelii é endêmica da Bahia, com distribuição em Floresta Atlântica no sul do estado (Smith \& Coile 2007; Loeuille 2014). F8, G8, H8, I8: Floresta Ombrófila Densa Submontana. Coletada com flores e frutos em fevereiro, junho, julho, setembro e outubro.

Material selecionado - Camamu, Acara, 13\%46'51"S, 3906'14"W, 40 m s.n.m., 2 jul. 1971 (fl. e fr.), T.S. Santos. 1722 (CEPEC). Ilhéus, Banco da Vitória/oeste da Mata da Esperança, 14²46'38"S, 3905'28"W, 52 m s.n.m., 28 set. 1994 (fl. e fr.), W.W. Thomas et al. 10674 (ALCB, CEPEC, HUESC). Itacaré, $14^{\circ} 16^{\prime} 39^{\prime \prime S}, 38^{\circ} 59^{\prime} 48^{\prime \prime W}, 29$ m s.n.m., 4 jul. 1996 (fl. e fr.), A.M. Carvalho et al. 6230 (CEPEC, RB). Porto Seguro, Parque Nacional Monte Pascoal, 16 26'59"S, 3903'53"W, 50 m s.n.m., 6 fev. 1999 (fl. e fr.), W.W. Thomas et al. 12050 (CEPEC). Una, Reserva

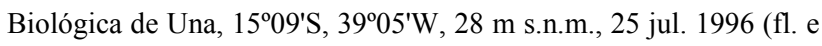
fr.), S.C. Sant'Ana et al. 612 (CEPEC). Uruçuca, fazenda Lagoa do Conjunto Fazenda Santa Cruz, 14 $35^{\prime} 35^{\prime \prime}$ S, 39 $9^{\circ} 17^{\prime} 04^{\prime \prime W}, 102 \mathrm{~m}$ s.n.m., 17 out. 1993 (fl. e fr.), W.W. Thomas et al. 9951 (CEPEC). 
Piptocarpha riedelii assemelha-se a $P$. pyrifolia pelo hábito arbustivo e folhas concolores marromescuras quando desidratadas. No entanto, $P$. riedelii apresenta folhas sem pontuações, inflorescências umbeliformes, pápus cerdosos marrom-dourados e cipselas compridas $(4,5-5 \mathrm{~mm}$ compr.), com pontuações glandulares (vs. folhas com pontuações glandulares marrons, inflorescências glomeruliformes, pápus alvos e cipselas curtas, 3,5-4,5 mm compr., sem pontuações glandulares em $P$. pyrifolia).

11.Piptocarpha robusta G.M.Barroso, Loefgrenia 36: 1; fig. 2. 1969.

Figuras 4 e $6 \mathrm{~K}-\mathrm{N}$.

Arbustos escandentes; ramos cilíndricos, ferrugíneo-estrelado-tomentosos, sem pontuações. Folhas elíptico-oblongas, $7,5-13,5 \times 4,5-9 \mathrm{~cm}$, subcoriáceas, ápice agudo a obtuso, base cuneada a arredondada, oblíqua, margem denticulada, face adaxial rugosa, com tricomas simples, face abaxial cinéreo-estrelado-tomentosa, sem pontuações, 7-10 pares de nervuras laterais, pecíolo ca. $1,5 \mathrm{~cm}$ compr. Inflorescências umbeliformes, capítulos pedunculados; invólucros (5-)7,5-9 × (3-)5-5,5 mm, ovoides a turbinados; brácteas involucrais imbricadas em 6 ou 7 séries, marrom-castanhas quando desidratadas, ápice levemente tomentoso, sem pontuações, agudo a acuminado, obtuso, margem esparsamente ciliada, brácteas externas ovadotriangulares, brácteas internas elípticas. Flores com tubo 5,5-6 (7) $\mathrm{mm}$ compr., lobos 3-3,5 $\mathrm{mm}$ compr.; anteras ca. $4,5 \mathrm{~mm}$ compr., base das tecas afilada, sem papilas, 1-1,5 mm compr. Cipselas maduras 3-4 mm compr., 3- ou 4-angulosas, fortemente 10-costadas, com pontuações ferrugíneas; pápus alvos, cerdas externas $0,5-1 \mathrm{~mm}$ compr., filiformes, cerdas internas 7-8 mm compr.

Piptocarpha robusta é endêmica do Brasil e está distribuída em áreas de Floresta Atlântica do sul da Bahia, Espírito Santo e Minas Gerais (Smith \& Coile 2007; Loeuille 2014). H8, I8: encontrada em Floresta Ombrófila Densa Submontana. Coletada com flores e frutos em maio e agosto.

Material selecionado - Eunápolis, Colônia, 16²2'19"S, 39³4'49"W, 189 m s.n.m., 18 maio 1971 (fl. e fr.), T.S. Santos 1670 (isótipo de Piptocarpha santosii H.Rob., CEPEC); Potiraguá,

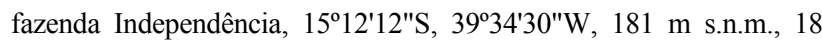
ago. 2006 (fl. e fr.), J.L. Paixão et al. 1056 (CEPEC, HUEFS, HUESC).

Material adicional examinado - BRASIL. ESPÍRITO

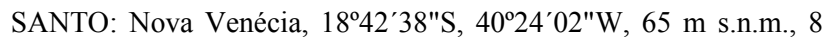
maio 1955 (fl. e fr.), A.P. Duarte 9758 (isótipo de Piptocarpha robusta G.M.Barroso, CEPEC, RB). MINAS GERAIS: Raul Soares, Vermelho Velho, 25 maio 1940 (fl. e fr.), M. Carmo s.n. (parátipo de Piptocarpha robusta G.M.Barroso, RB).

Piptocarpha robusta é reconhecida por apresentar folhas elíptico-oblongas com face adaxial rugosa e margem levemente denticulada, inflorescências densamente umbeliformes e capítulos ovoides a turbinados. Piptocarpha santosii é sinônimo desta espécie (Smith \& Coile 2007).

12.Piptocarpha rotundifolia (Less.) Baker subsp. rotundifolia in Martius, Fl. Bras. 6(2): 125; t. 28. 1873.

Figuras 5 e 60 .

Árvores ca. $3 \mathrm{~m}$ alt.; ramos cilíndricos, cinéreoestrelado-tomentosos, sem pontuações. Folhas orbiculares, obovadas, 3,5-6(-8) × 3-6 cm, coriáceas, irregularmente revolutas, ápice obtuso, base arredondada a subcordada, margem inteira e revoluta, discolores, face adaxial rugosa, sem pontuações, face abaxial cinérea-ferrugínea-estrelada-tomentosa, pontuações ausentes, 5 ou 6 pares de nervuras laterais, pecíolo $\quad 1-1,5 \quad \mathrm{~cm}$ compr. Inflorescências umbeliformes, capítulos sésseis; invólucros 7-10 × ca. $2 \mathrm{~mm}$, ovoides a cilíndricos; brácteas involucrais imbricadas em 6-8 séries, castanhas quando desidratadas, ápice tomentoso, com pontuações hialinas, agudo, margem escassamente ciliada, brácteas externas ovadas, brácteas internas elípticas a lineares. Flores com tubo 4,5-5 mm compr., lobos 3,5-4 mm compr.; anteras 4,5-5 $\mathrm{mm}$ compr., base das tecas afilada, sem papilas, ca. $1 \mathrm{~mm}$ compr. Cipselas maduras 3-4 mm compr., 3-angulosas, indistintamente costadas, sem pontuações; pápus ferrugíneos, cerdas externas $0,5-2 \mathrm{~mm}$ compr., filiformes, cerdas internas 5,5-6 mm compr.

Piptocarpha rotundifolia subsp. rotundifolia é endêmica do Brasil e está distribuída em áreas de Cerrado da Bahia, Distrito Federal, Goiás, Minas Gerais, São Paulo e Paraná (Smith \& Coile 2007; Loeuille 2014). G2, G3, G7: Cerrado e Caatinga Arbórea Aberta. Coletada com flores e frutos em janeiro, maio a julho, outubro e dezembro.

Material selecionado - Correntina, $14^{\circ} 10^{\prime} 04^{\prime \prime} \mathrm{S}, 46^{\circ} 00^{\prime} 25^{\prime \prime} \mathrm{W}$, 561 m s.n.m., 18 maio 2001 (fl. e fr.), F. França et al. 3701 (ALCB,

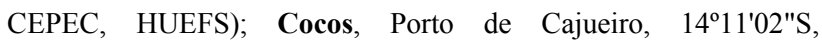
4432'04"W, 559 m s.n.m., 6 jun. 1984 (fl. e fr.), S.B. Silva et al. 386 (ALCB, CEPEC, RB); Vitória da Conquista, 14 $51^{\circ}$ '58"S, 40 50'22"W, 923 m s.n.m., 10 out. 1938 (fl. e fr.), C. Torrend 163 (ALCB).

Piptocarpha rotundifolia subsp. rotundifolia é o único táxon de Piptocarpha encontrado nas áreas do cerrado da Bahia. É reconhecida por apresentar porte arbóreo, folhas coriáceas, irregularmente revolutas e orbiculares, capítulos com brácteas compactamente imbricadas e cipselas robustas. Segundo Smith \& Coile (2007), difere de P. rotundifolia subsp. hatschbachii G.Lom.Sm. pelas folhas orbiculares (vs. elípticas na subsp. hatschbachii). Estas informações serviram como suporte para a identificação desta subespécie. Na lista de espécie da flora do Brasil, Loeuille (2014) cita pela primeira vez a ocorrência desta espécie na Bahia. 

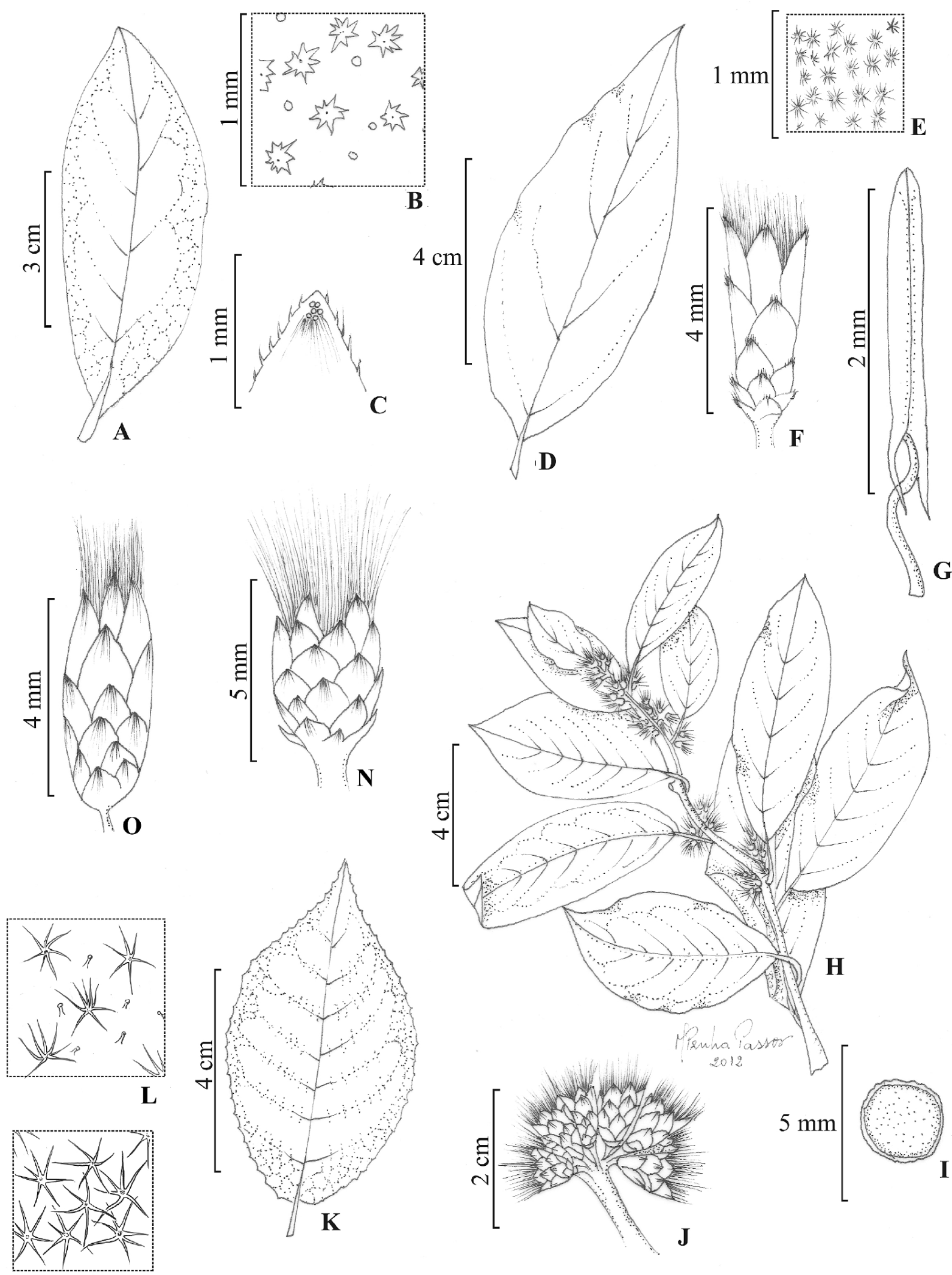

M

Figura 6. A-C. Piptocarpha pyrifolia: A- lâmina foliar; B- detalhe da face abaxial da lâmina foliar, evidenciando os tricomas e as pontuações; C- detalhe do ápice da bráctea, evidenciando as pontuações; D-G. P. ramiflora: D- lâmina foliar; E- tricomas; F- invólucro; Gantera em vista lateral; H-J. $P$. riedelii: H- ramo com inflorescências; I- detalhe do ramo em corte transversal; J- inflorescência; K-N. $P$. robusta: K- lâmina foliar; L- detalhe da face adaxial da lâmina foliar, evidenciando os tricomas; M- tricomas; N- invólucro; O. $P$. rotundifolia: invólucro. (A-C-Sant'Ana 582; D-G-Amorim 2449; H-J- Sant'Ana 612; K-N- Paixão 1056; O- França 3701). 


\section{Agradecimentos}

À FAPESB, pela bolsa de Iniciação Científica concedida a M.Z.C., e ao CNPq, pela bolsa de Produtividade em Pesquisa concedida a AMA (Processo 306992/2012-4) e pelo financiamento desta pesquisa (Processo 563548/2010-0).

\section{REFERÊNCIAS}

Barroso, G.M. 1959. Flora do Rio de Janeiro Compositae. Rodriguésia. 33/34: 69-155.

Funk, V.A. et al. 2009. Classification of Compositae. In: V.A. Funk, A. Susanna, T.F. Stuessy \& R.J. Bayer (eds), Systematics, Evolution, and Biogeography of the Compositae. IAPT, Vienna, p. 171-189.

Loeuille, B. 2014. Piptocarpha. In: Lista de Espécies da Flora do Brasil. Jardim Botânico do Rio de
Janeiro. Disponível em <http://floradobrasil.jbrj. gov.br>; acesso em 12 out. 2014.

Nakajima, J. et al. 2014. Asteraceae. Lista de Espécies da Flora do Brasil. Jardim Botânico do Rio de Janeiro. Disponível: <http://floradobrasil. jbrj.gov.br>. Acesso em: 12 out. 2014.

Robinson, H. 2002. Three new species of Piptocarpha (Asteraceae: Vernonieae) from Ecuador and Peru. Novon 12: 393-398.

Roque, N. \& Bautista, H.P. 2008. Asteraceae: caracterização e morfologia floral. Edufba, Salvador.

Smith, G.L. 1981. New taxa in Piptocarpha R. Br. (Vernonieae: Compositae). Annals of the Missouri Botanical Garden 68: 661-667.

Smith, G.L. 1982. Taxonomic considerations of Piptocarpha (Compositae: Vernonieae) and new taxa in Brazil. Brittonia 34: 210-218.

Smith, G.L. \& Coile, N.C. 2007. Piptocarpha (Compositae: Vernonieae). Flora Neotropica Monograph 99: 1-94.

\title{
LISTA DE EXSICATAS
}

\begin{abstract}
Alves, L.J. 314 (1); Amorim, A.M. 1347 (8), 1377 (4), 1410 (1), 2449 (9), 2540 (4), 2643 (8), 3136 (2), 3611 (6), 5245,5538 (4), 6342 , 7688 (7); Belém, R.P. 25 (12), 1546 (9), 1571 (9), 1820 (8), 1831 (8), 1834 (8), 2651 (7), 2654 (4), 2646 (4); Borges, R.A.X. 279 (6); Cardoso, D. 2124 (8); Carvalho, A.M. 397 (3), 3618 (10), 4227 (3), 4974, 5143, 5538 (4), 6230 (10); Daneu, L. 108 (7), 116 (8); Duarte, A.P. 3719 (6), 6147 (8), 6834 (4), 9758 (11); Ferreira, F.M. 1532 (5), 1895 (2); Filgueiras, T. S. 1679 (12); França, F. 3701 (12); Guedes, M.L. 6758 (8), 6759, 9521 (4), 10005 (8), 17931 (2); Guimarães, J.G. 1368 (12); Gusmão, E. 497 (3); Hage, J.L. 787 (10); Hatschbach, G. 1091 (7), 46807 (9), 57989 (5), 68523 (8); Heringer, E.P. 9465 (6); Jardim, A.B. 65(7); Jardim, J.G. 175 (10), 182,279 (8), 660 (10), 1895 (2), 5307 (7); King, R.M. 8020 (1); Lima, S. 139 (4); Liuth, H.S. 84 (6); Lopes, M.M. 1554 (6); Marquete, R. 414 (6); Martini, A. 42 (12), 43 (8); Moraes, P.L.R. 2945 (1); Mori, S.A. 10769 (5), 12754 (8), 12883 (5); Nascimento, F.H.F. 75 (5); Paixão, J.L. 1056 (11); Pirani, J.R. 7464 (2); Pinheiro, R.S. 289 (4), 267 (9), 1312 (10), 1937 (4); Queiroz, L.P. 1062 (2); Ramos, C.E. (2); Rocha, D. 1132 (6); Sambuichi, R. 555 (2); Sant'Ana, S.C. 27, 558 (8), 575 (4), 582 (8), 612 (10); Santos, T.S. 182 (1), 1670 (11), 1722,1760 (10), 1959,2450 (8), 4401(4); Silva, L.A.M. 3842 (4), 1786 (7), 2579 (8), 3845 (10); Silva, M.A. 1282 (12); Silva, S.B. 386 (12); Torrend, C. 163 (12); Thomas, W.W. 9951,10674 (10), 10685, 11324 (4), 11413 (1), 11503 (4), 11870 (8), 12050, 19674 (10); Viollati, L.G. 164 (12).
\end{abstract}

